\title{
RELENDO CONTOS DE MACHADO DE ASSIS PELA IRREVERÊNCIA DE ALBERTO MUSSA: UM TRABALHO DE QUESTIONAMENTO E RECRIAÇÃO
}

\author{
RE-READING MACHADO DE ASSIS' SHORT STORIES \\ THROUGH ALBERTO MUSSA'S IRREVERENT LENSES: \\ QUESTIONING AND RECREATING
}

Diana Menasché ${ }^{1}$

\begin{abstract}
RESUMO: A proposta do livro Recontando Machado (2008) é oferecer narrativas complementares, paralelas ou mesmo conflitantes aos contos de Machado de Assis, desde que criativamente baseadas neles. No âmbito geral, experiências de recriaçấo. Aqui, nosso foco será a criaçăo de Alberto Mussa, "A Leitura Secreta", inspirada principalmente por A Cartomante e, secundariamente, por A Causa Secreta. Trata-se de uma meta-narrativa, pois o personagem principal, também narrador em primeira pessoa, é nada menos que um escritor convidado por Marco Lucchesi, seu amigo, a participar da redaçâo de uma obra crítica: uma Enciclopédia Machado de Assis. Assim, ele está incumbido da criaçâo de verbetes, que muito humoristicamente se multiplicam em exponencial. O estudo do irreverente conto "A Leitura Secreta" abre novas portas de interpretaçăo aos contos de Machado de Assis.
\end{abstract}

Palavras-chave: Machado de Assis. Alberto Mussa. Recriaçāo.

ABSTRACT: The idea of the volume "Recontando Machado" (2008) is to offer narratives which can be either a complement, or a parallel concept or a even a conflict to Machado de Assis' stories, as long as creatively based on these. In general, an experience of recreation. Our focus here will be Alberto Mussa's creation, "A Leitura Secreta", inspired mainly by "A Cartomante", but also by "A Causa Secreta". It is a meta-narrative, in that the central character, who works as first person narrator as well, is none less than a writer invited by Marco Lucchesi, his friend, to participate in the writing of a critical work: a Machado de Assis Encyclopedia. Thus, he is responsible for the creation of entries, which in the spirit of humor multiply themselves exponentially. The study of the irreverent short-story " $\mathrm{A}$ Leitura Secreta" opens new doors for the interpretation of Machado de Assis' stories.

Keywords: Machado de Assis. Alberto Mussa. Recriation.

A proposta do livro Recontando Machado, publicado em 2008, quando do Ano Nacional de Machado de Assis, é oferecer narrativas complementares, paralelas ou mesmo conflitantes aos contos de Machado de Assis, desde que criativamente baseadas neles. No âmbito geral, experiências de recriaçăo. Doze autores já publicados

University of Massachusettsat Amherst. A manutençâo do texto em normas da MLAé de responsabilidade da autora.dianamenasche@gmail.com 
anteriormente pela Editora Record foram convidados a participar da experiência de diálogo: livremente selecionando um ou mais de um conto do Bruxo do Cosme Velho, recriar o plot, transformar os personagens, preencher lacunas - de alguma maneira, re-visitar o fato narrado.

A presente reflexăo pretende explorar exatamente essa possibilidade oferecida pelo organizador do volume, Luiz Antonio Aguiar: cotejando original/recriaçâo, o objetivo é sondar o trabalho de um, com o estímulo oferecido pelo outro, buscando dentro do possível rever temas de narrativa e estilo. Os encadeamentos de fatos, bem como as descriçōes originais, serâo vistos por novos prismas.

Cada narrador contemporâneo se entregou a uma experiência distinta: por um lado, por sua personalidade e seu estilo como escritor; por outro, pelos próprios limites oferecidos pela obra-referência. O texto de Alberto Mussa, A Leitura Secreta, é inspirado principalmente por A Cartomante e, secundariamente, por A Causa Secreta. Trata-se de uma meta-narrativa, pois o personagem principal, também narrador em primeira pessoa, é nada menos que um escritor convidado por Marco Lucchesi, seu amigo, a participar da redaçăo de uma obra crítica: uma Enciclopédia Machado de Assis. Assim, ele está incumbido da criaçáo de verbetes, que muito humoristicamente se multiplicam em exponencial. Seu primeiro verbete é um resumo do conto A Cartomante, logo desdobrado em catorze verbetes. O próprio Lucchesi lhe pergunta se ele năo desejaria incluir um verbete para o(a) autor(a) das "cartas anônimas", e esse convite desencadeia toda uma série de especulaçóes por parte do narrador / escritor, que se vê envolvido em múltiplas hipóteses interpretativas.

A partir de uma pergunta - quem será o autor das cartas?-, com a ramificaçăo em inúmeras possibilidades que geram outras possibilidades, o autor mergulha num mar especulativo sobre o conto que lhe cabia formatar em verbetes e, no caminho, ainda o compara com outro conto machadiano: A Causa Secreta .

O humor candente na obra de Alberto Mussa é reforçado pela descriçâo dos diálogos entre o tal escritor-convidado e Lucchesi, diálogos esses que incluem tanto elogios de um para outro, quanto conflitos, coroados até com uma batida de telefone na cara. Esse desmembramento do autor real, que coloca-se nas duas vozes, questionando-se ininterruptamente, permite ao leitor uma viagem entre hipóteses interpretativas umas mais alucinadas do que as outras. O ceticismo de um ouvinte, sua reaçăo fria e desinteressada, ou o intenso choque nele provocado, é que trazem o elemento de comédia, junto com a delirante absurdidade (à primeira vista) ou imprevisibilidade de algumas das leituras. Por meio do diálogo, o "autor" náo precisa se comprometer, pois pode manter sempre na voz do outro o elemento de contraponto. Esta dialética gera um produto rico em ramificaçôes criativas.

Assim, em síntese, o que temos năo é propriamente uma recriaçăo direta dos contos, mas releituras destes no contexto da produçâo de verbetes para uma Enciclopédia que, no fim, năo pode se materializar: "Obcecado pelo conceito de obra aberta, [Lucchesi] elevou a tal ponto o orçamento da Enciclopédia que os patrocinadores desistiram do projeto. Náo quero culpá-lo por isso." (39) Trata-se, enfim, de uma completa ironia, em que Mussa se permite brincar com a própria organizaçăo do livro por Aguiar: "Luiz Antônio Aguiar, que pensou em publicar estas memórias, foi quem me apontou uma suposta inconsistência: (...)". (39) 
É preciso compreender que todas as interpretaçōes săo oferecidas com o máximo de provas, de modo a se justificarem no contexto do conto de Machado, e se adequarem aos pormenores do plot. Ao mesmo tempo, por seu caráter inusitado, podem às vezes simplesmente parecer absurdas. Por isso fazemos questăo de citar: "Era uma questăo fundamental do texto: considerar a mulher uma simples vigarista, incapaz de ler o destino, mas esperta o suficiente para dizer o que os consulentes queriam ouvir, era ir pelo senso comum; e quem lê Machado náo pode adotar essa via." (33) Este comentário nos parece fundamental, porque aqui se revela o que o organizador de verbetes está fazendo: ele está mais do que evitando a via do senso comum, condenando-a. Para efeitos de humor, isso é estriônico, e sem dúvida é nesse espírito que fica tal achado. Mas a bem de uma análise distanciada, caberia voltar a trazer a problemática à tona: será que quem lê Machado năo pode adotar a via do senso comum? Vamos trabalhar sobre isso.

O jogo de interpretaçōes proposto no texto de Mussa praticamente só é possível se algumas condiçôes forem aceitas: 1) é preciso buscar sentidos para além do sensocomum; 2) Machado nâo comete "erros" em suas narrativas; tudo que lá se encontra foi pensado para ser pelo leitor concatenado e 3) a obra está completa e incompleta ao mesmo tempo; ela se fecha em si mesma, e nesse sentido náo pode ter contradiçôes ou pecar por falta de lógica, mas ela pode ter (e de fato tem) lacunas que devem ser preenchidas pelos leitores, nos limites da plausibilidade com a narraçăo exposta. O autor trabalha com a noçấo de obra aberta, uma obra que se oferece à finalizaçấo nas máos dos leitores. Trata-se de um procedimento usado também (em outros livros e teses) para a busca de respostas na relaçăo entre Capitu e Bentinho, do romance Dom Casmurro, numa dialética entre o quanto pode ser "imaginado" e/ ou "adicionado" e o quanto deve estar marcado no texto. No caso de Machado, por haver ambiguidades deixadas ao sabor da leitura, as margens sâo distendidas.

Entretanto, para poder nos entregarmos a este jogo radical, precisamos primeiro nos dedicar à simples leitura da obra, destacando-se fatos elementos importantes, dentro do chamado senso comum, o qual depois se irá questionar, com as aberturas oferecidas pelas elipses da narrativa.

\section{BUSCANDO A TESE DO CONTO}

A primeira frase de um conto chama a atençăo por si mesma: simplesmente por estar posicionada ali, como primeira frase. Quando, adicionado a esse valor - ou poder - intrínseco, há ainda o fato de a mesma frase trazer uma tese, e esta tese ser atribuída a um famosíssimo personagem da literatura canônica universal, ela atrai para si ainda mais atençáo, e adquire mais peso. E, náo bastasse esses dois aspectos, se a mesma frase, ou a tese nela contida, é ainda repetida clara e explicitamente duas vezes mais no conto (que, convém sempre reforçar, sendo um texto curto, tende a ter cada uma de suas palavras mais ou menos pesada), năo há questionamento de que ela parecerá, no mínimo, bem relevante para uma discussăo sobre o que se passa no conto.

É isso o que acontece no conto A Cartomante. A primeira frase, "Hamlet observa a Horácio que há mais cousas no céu e na terra do que sonha a nossa filosofia." (132), volta aos olhos do leitor em "Foi entăo que ela, sem saber que traduzia Hamlet em 
vulgar, disse-lhe que havia muita cousa misteriosa e verdadeira neste mundo." (132), e ainda "e a mesma frase do príncipe de Dinamarca reboava-lhe por dentro: 'Há mais cousas no céu e na terra do que sonha a filosofia..."'(137). Com estas três mençôes, num conto de poucas páginas, sem dúvida a frase ganha uma dimensâo muito importante, e a pergunta que surge é: será que o conto apóia a mesma tese, a contraria, ou faz algo totalmente distinto?

Năo somente por a cartomante aparecer como uma falsária (diante de um público extasiado e embasbacado), mas também porque o fim do conto é o assassinato de Rita e de Camilo, numa leitura feita com "bom senso", ou com "senso comum", o autor está usando a frase para efeito de ironia. Isso é reforçado pela maneira como o narrador, ao exagerar as reaçóes de Camilo, torna-as um pouco ridículas: "Camilo, maravilhado, fez um gesto afirmativo." (137); “Camilo tinha os olhos nela [cartomante], curioso e ansioso" (137); "Camilo inclinou-se para beber uma a uma as suas palavras" (137); "Camilo estava deslumbrado" (138). Toda esta reaçâo apaixonada de Camilo provoca a reaçâo contrária no leitor, que passa a ser um observador distanciado, uma vez que o elemento do exagero causa precisamente o ponderar no receptor. Afinal, se aceitamos o narrador em terceira pessoa e nâo o consideramos de antemăo um mentiroso, teremos que "Camilo estava deslumbrado", mas năo "a situaçâo era deslumbrante", que sâo coisas bem distintas. Nesse contexto, a frase de Hamlet aparece na história antes do mais para ser contradita pelos "fatos da vida", dentre eles a morte. Outra funçâo seria a de justificar a decisăo de Camilo, revelando o que se passou no seu coraçăo ao decidir descer do tílburi e ir também à cartomante. Foi o eco dessa frase de Hamlet que o moveu à casa das janelas fechadas.

A voz do conto, porém, permanece sendo a voz de ceticismo, coroado com ironia. É de se ressaltar que Rita é chamada de tonta (133), em e a mâe de supersticiosa (132) (e para a superstiçâo em si, o narrador usa a expressăo "vegetaçâo parasita" (133)), e que Camilo ri de Rita por esta ter ido à cartomante. Ela lhe responde: "Ria, ria. Os homens sâo assim (...)" (132), mas o fato é que o conto nâo vem a dar razăo mais tarde a Rita; quer dizer, năo é que este "ria, ria" seja dito para o leitor, e que logo adiante se revele que Rita era quem estava certa. Muito pelo contrário, esta personagem feminina aparece cada vez como mais "tonta" na descriçăo do narrador, sendo também chamada de serpente, mesmo que em outro contexto ("como uma serpente, foi-se acercando dele" (134)).

Prova mais cabal ainda de que o sumo do conto é a ironia, e de modo algum uma apologia à literatura fantástica, Rita e Camilo văo à cartomante para buscar conforto, quando a primeira sabe que está traindo o marido, e o segundo, o amigo. Camilo sabe, claro, que está envolvido com uma mulher casada, e esta, o evidente náo precisaria ser dito, sabe que é casada. $O$ que ambos procuram na cartomante parece ser uma espécie de proteçâo ou consolo: eles querem escutar que está tudo maravilhoso, e o futuro é brilhante. A cartomante sabe que deve sempre fazer o cliente feliz, e aproveita-se de Rita (pelo que ouvimos ela contar) e de Camilo (pelo que testemunhamos diretamente como leitores-presentes, na descriçâo do encontro). Entretanto, os dois morrem logo, assassinados por Vilela, o marido de Rita. No máximo, podemos entender (se seguirmos o "bom senso") a frase do personagem de Shakespeare como significando: existe mais entre o céu e a terra do que o que você sonha quando está ouvindo uma cartomante. Os desesperados vâo às cartomantes para ouvir o que querem ouvir, e o fím é a morte. 


\section{ELIPSES: AS OMISSÕES DO BRUXO}

Dito isso, passamos a algumas questôes que săo fonte de inspiraçăo à criatividade exuberante de Alberto Mussa. A primeira delas é uma elipse do conto de Machado, entre o momento em que Camilo escuta falar da casa da cartomante, e o momento em que a vê, quando passa por ela. As linhas săo: "- Onde é a casa?" (132), "- Aqui perto, na rua da Guarda Velha; năo passava ninguém nesa ocasiăo." (132) Alguns parágrafos depois: "Esta [Rita] desceu pela rua das Mangueiras, na direçăo de Botafogo, onde residia; Camilo desceu pela da Guarda Velha, olhando de passagem para a casa da cartomante." (133) Como nada foi dito sobre o número da casa, ou mesmo suas características físicas, a rigor fica a questăo: poderia Camilo ter adivinhado qual era casa, ainda mais numa rua tâo ampla como a a da Guarda Velha? É claro que com uma leitura no estilo "senso comum", pensaríamos que se trata apenas de uma elipse. Uma vez que ele sabe a rua, tem como achar, perguntando para as pessoas no local, ou inferindo por si mesmo, se já estiver familiarizado com as outras casas. Na pior das hipóteses, parece um "erro" de Machado, ou uma omissâo sem maior repercussâo. Esta omissâo, entretanto, faz germinar hipóteses interpretativas na narrativa metaficcional de Mussa.

A outra omissâo - esta proposital, e incorporada à trama - é a do autor das cartas a Camilo. Trata-se de uma dupla omissăo, pois as cartas săo anônimas do começo até o fim da narrativa. A primeira apariçâo: "Um dia, porém, recebeu Camilo uma carta anônima, que lhe chamava imoral e pérfido, e dizia que a aventura era sabida de todos." (134) Depois, a insistência, e a interpretaçăo de Rita: "Camilo recebeu mais duas ou três cartas anônimas, tăo apaixonadas, que năo podiam ser advertência da virtude, mas despeito de algum pretendente; tal foi a opiniấo de Rita (...)." (135). Logo, a sugestăo da moça:"- Bem, disse ela; eu levo os sobrescritos para comparar a letra com a das cartas que lá aparecerem; se alguma for igual, guardo-a e rasgo-a..." (135). Finalmente, o cálculo de Camilo: "era natural uma denúncia anônima, até da própria pessoa que o ameaçara antes" (135). Em momento algum, apesar de termos um narrador com acesso ao coraçáo dos personagens, chegamos a saber quem era realmente o autor das cartas. Uma hipótese com bom teor de "bom senso", ou "senso comum", para nos atermos à expressăo oferecida por Mussa, é a de que Vilela é o autor das cartas. Ele dá uma chance, e outra, e outra, para a mulher e o amigo, até que decide matá-los. Outras hipóteses, com mais ou menos bom senso, sâo desenvolvidas criativamente em A Leitura Secreta, e mais adiante trabalharemos sobre hipóteses possíveis.

Assim, já temos cartas de que nâo se sabe a autoria; o reconhecimento de uma casa que nâo é explicado; a estes dois elementos, adiciona-se o "mistério" de como poderia a cartomante saber exatamente o que dizer para Rita e para Camilo. É bem verdade que ela aposta em frases genéricas, e com isso já teríamos a explicaçâo. Por exemplo, se um homem chega no meio do dia, assustado, e sem ter marcado hora, é claro que a cartomante pode começar com uma frase do tipo: "O senhor tem um grande susto..." (137). Por experiência, ela pode saber que é coisa de amantes, ou mesmo, neste caso, pode até estar por dentro das fofocas, e já conhecer que tal rapaz é Camilo, e que ele é amante de Rita. Pode mesmo ser que Rita contou tudo, quando foi pedir conselhos e orientaçăo da cartomante, como aliás fazem várias mulheres, quando pedem estes serviços. Esta, uma vez mais, é a interpretaçăo "senso comum", com base na própria narrativa de Machado, na ironia do final, e no que conhecemos 
sobre o estilo dele. É difícil, para năo dizer impossível, crer que o conto leve a pensar que a cartomante esteja realmente adivinhando o que se passa com o cliente.

Quando Camilo pergunta a Rita: “Tu crês deveras nessas cousas?" (132), ele está abrindo uma porta para que ela se expresse. Isso é fundamental para que depois a reaçấo dele de ir à cartomante também pareça ainda mais impressionante. É possível acompanhar a mente de um cético que, em momento de desespero, se entrega ao que antes considerava motivo de riso e chacota. Adiante, até lemos, com relaçâo à reaçâo dele de si para si: "Às vezes queria rir, e ria de si mesmo, algo vexado (...)" (139) Contudo, como a reaçấo dele ante a quiromancia é ridicularizada pelo narrador, e ele morre no fim, é improvável que o leitor se identifique com a mudança de comportamento, e transforme-se, junto com Camilo, na direçăo de acreditar no poder das cartomantes. Em todo o caso, e para todos os efeitos, fica omitido no conto se a cartomante tem ou nâo tem alguma capacidade de prever o futuro, o ler o presente.

Outra omissăo fundamental é o nível de conhecimento de Vilela sobre os fatos. Em nenhum momento somos informados sobre o estatus de sua informaçăo. Nâo sabemos se ele sabe que sua esposa tem um caso com outro homem, năo sabemos se ele sequer suspeita disso. Tampouco temos a menor sombra sobre se ele vem a descobrir ou năo, e se alguém conta para ele ou năo - e quando e como tudo isso acontece. Na realidade, mesmo na cena do assassinato, nâo há qualquer indicaçâo explícita do motivo de seu ato. Esse total silêncio da narraçáo abre espaço para muitíssimas interpretaçōes. Vilela descobre a traiçăo? Quando? Em que contexto? Vilela decide se vingar? Quando? E por que dessa maneira? E por que com essa estratégia? Como o leitor náo sabe o que se passou na casa entre Vilela e Rita antes de Camilo chegar, náo há a menor pista do que Rita falou ou deixou de falar, e do que motivou o comportamento do marido traído. A leitura mais senso comum possível é de que Vilela descobre a traiçăo (diretamente, vendo algo; ou indiretamente, sendo informado por alguém), e entăo ou decide primeiro alertar o casal (é, nesse caso, autor das cartas, pedindo apenas que alguém as redija, para năo ter sua caligrafia), e depois parte para o assassinato, ou entâo ele é alertado pelo mesmo autor/a das cartas, que escrevia para Camilo, e imediatamente decide pelo assassinato. Já que este ato se dá no meio do dia, e pelas próprias máos dele, há quem possa pensar que foi uma decisâo mais ou menos espontânea, impulsiva, nâo tanto algo planejado. Neste caso, ele teria de ter descoberto tudo naquele dia, anulando a hipótese de ser o próprio autor das cartas.

E ainda, outra grande elipse da narrativa está na descriçăo física da cartomante. A luz bate no rosto de Camilo, o que indica que ele deve ter dificuldade para ver o rosto da cartomante muito bem, mas isso é um detalhe que discutiremos mais adiante. Ela năo o olha de frente, mas "por baixo dos olhos" (137). E sabemos que: "Rápido pegou outra vez as cartas e baralhou-as, com os longos dedos finos, de unhas descuradas (...)" (137); assim como "tirou um cacho destas, começou a despencá-las e comê-las, mostrando duas fileiras de dentes que desmentiam as unhas. Nessa mesma açăo comum, a mulher tinha um ar particular." (138) Nâo temos qualquer indicaçâo sobre o seu rosto ou o seu corpo, mesmo suas vestimentas. Apenas sabemos que os dentes contradizem as unhas, o que para além de uma descriçăo, é uma metáfora interessantíssima, podendo significar que o que ela mostra na verdade é diferente do que guarda por dentro. Para efeitos práticos, nâo sabemos porque a mulher de dentes bem cuidados se expóe com as unhas sujas, e 
numa casa de má aparência. O narrador sugere: "Velhos trastes, paredes sombrias, um ar de pobreza, que antes aumentava do que destruía o prestígio." (137) Tudo isso abre espaço para a imaginaçăo. E ainda é de se destacar que a cartomante năo tem nome.

\section{ESTILO NARRATIVO DE MACHADO DE ASSIS}

Neste conto em particular, encontramos elementos típicos de Machado na forma de guiar o leitor. Se no âmbito do conteúdo Machado deixa muitos espaços abertos e ambiguidades, na mecânica da narrativa ele tende a ser quase didático, esclarecendo bem cada passo e conectando os pontos quando ocorrem flashbacks. Um bom exemplo está em: "Vilela, Camilo e Rita, três nomes, uma aventura, e nenhuma explicaçâo das origens. Vamos a ela." (133) Em vez de simplesmente partir para a descriçăo (coisa que de fato o leitor espera, desde que viu o nome Vilela pular em cena sem qualquer antecedente: "Vilela podia sabê-lo, e depois..." (132), e passou a imaginar se năo é pai, ou irmáo, ou outro parente da mulher), Machado explica o que está fazendo, revelando o lado de trás da tapeçaria em que costura. Quando ele alcança o ponto da narrativa em que a primeira cena se explica, o narrador lembra ao leitor: "Vimos que a cartomante restituiu-lhe a confiança, e que o rapaz repreendeu-a por ter feito o que fez."(134) Em outras palavras, Machado pode deixar o leitor curioso, mas năo o deixa perdido.

Outra característica da literatura machadiana é o uso de metáforas e imagens para descrever o estado e a açăo de seus personagens. Neste conto, temos vários exemplos, alguns dos quais estando em: "No dia em que deixou cair toda essa vegetaçâo parasita, e ficou só o tronco da religiăo, ele, como tivesse recebido da măe ambos os ensinos (...)" (133) , e ainda no mesmo parágrafo: "diante do mistério, contentou-se em levantar os ombros, e foi andando" (133). Também "A velha caleça de praça, em que pela primeira vez passeaste com a mulher amada, fechadinhos ambos, vale o carro de Apolo." (134) e "Năo tardou que o sapato se acomodasse ao pé, e aí foram ambos, estrada fora, braços dados, pisando folgadamente por cima de ervas e pedregulhos (...)" (134)

Um terceiro ponto que aqui destacamos na percepçăo do estilo narrativo típico do autor é o fato de ele embalar o leitor nas sensaçóes do personagem de uma maneira completamente envolvente. É chocante perceber que desde "Camilo ia andando inquieto e nervoso" (136), o que se dá mais ou menos no meio da narrativa, em termos quantitativos - quer dizer, de contagem de linhas - desde esta frase, o que acontece é que ele está correndo para a morte.

\section{A RELAÇÃO DO CONTO DE MUSSA COM O DE MACHADO}

É interessante remarcar que Mussa năo está buscando copiar o estilo de Machado, suas marcas autorais, vocabulário, ou particularidades. O que seu conto propóe é uma viagem em hipóteses interpretativas, abusando da liberdade oferecida pelas elipses ou ambiguidades de Machado. Com um narrador que é colaborador de uma Enciclopédia, e o organizador da Enciclopédia a contrapô-lo, todas as hipóteses podem ser questionadas. Nesse sentido, nenhuma hipótese é levada num clima de total seriedade. A primeira marca de humor no texto está provavelmente no elogio que o organizador faz ao colaborador, que na realidade se chama "Mussa", o nome do autor, embora a história 
seja fictícia: "- Mussa, você é um gênio! - me disse Marco, pelo telefone. Agradeci, chamei-o carinhosamente 'Bruxo de Tribobó', trocamos elogios por mais alguns minutos e retomei conto." (22) Há entăo muitíssimas outras, das quais destacamos: "- Marco, meu prezado, você acha que o Bruxo aceitava a teoria de Shakespeare?", "- Mussa, caríssimo, Machado foi um pândego. Ponha isso na cabeça." (27) E finalmente: "Como forma de protesto [contra as interpretaçóes enviadas por outros colaboradores, que confundiam as suas próprias], passei eu também a enviar colaboraçôes. O sucesso foi estrondoso. Numa delas, por exemplo, provei que Esaú e Jacó era uma transposiçăo de mitos ameríndios em que Sol e Lua figuram como gêmeos antagônicos." (32) Ao ver o deboche que ele faz de si mesmo, entendemos que o texto todo năo está lá para ser levado "a sério", como mencionamos antes, e sim deve ser entendido como uma experiência de questionamento e humor. Nâo há limites para a experiência, que vai até o absurdo, exceto que os fatos precisam se enquadrar perfeitamente nas brechas deixadas por Machado - mesmo que a lógica, ou bom senso, seja corrompida.

Um exemplo da atitude de "Mussa", o personagem, é interpretar que Vilela queria, espontaneamente, ser corno, e ser lembrado como corno no futuro: "tomar a atitude mais radical, que o imortalizasse como corno" (39). É claro que nâo há indícios no conto original para concluir que Vilela ama ser o marido traído, mas o fato de Camilo e Rita irem ao teatro juntos, lerem os mesmos livros, jogarem à noite, é para Mussa prova de que Vilela tinha de saber o que estava se passando, e năo fazia nada a respeito porque gostava que assim fosse.

É nessa mesma linha que oferecemos múltiplas interpretaçōes, seguindo o caminho trilhado por Mussa - autor. O conto de Machado inspirou-o, e o dele nos inspirou também.

Quem é o autor dar cartas anônimas? Começamos com a hipótese de que Rita tem razăo em seu cálculo, e as cartas anônimas sâo escritas por ninguém menos que uma pretendente de Camilo. A hipótese surge em: “Camilo recebeu mais duas ou três cartas anônimas, tăo apaixonadas, que năo podiam ser advertência da virtude, mas despeito de algum pretendente; tal foi a opiniăo de Rita, que, por outras palavras mal compostas, formulou este pensamento: (...)". (135) De fato, a essa altura, a mulher já foi chamada de tonta, desconfiada e medrosa (134), o que lhe traz descrédito. Apesar disso, ela é reconhecida por falar algo semelhante ao personagem de Shakespeare e, aqui, tem o crédito por falar algo absolutamente machadiano, somente com as palavras náo encaixadas. Neste sentido, o conto nos deixa pensar que ela poderia ser estar falando algo com propriedade, apesar da falta de termos. Se Rita está certa, entăo de fato há um pretendente ou uma pretendente.

1) Primeiro, destacamos o termo pretendente, pois assim diz o texto (135). Mesmo que fosse coisa da época escrever assim (como o poeta para uma mulher), a inclusăo do masculino abre a hipótese de que o pretendente seja o próprio Vilela, apaixonado por Camilo. Hipótese à la Veríssimo, e também Tatiana Salem Levy (autora presente em Recontando Machado), claro. Vilela tem ciúmes da esposa e năo vê a hora de que o relacionamento acabe, para que possa ficar com um dos seus melhores amigos. Ao perceber que náo terá chances de jeito nenhum, comete os assassinatos passionais.

2) Mas se Rita está certa, pode ser também que a dona da casa onde eles se encontram seja apaixonada por Camilo. (A frase no conto é: "A casa do encontro era na antiga 
rua dos Barbonos, onde morava uma comprovinciana de Rita." (133) Como esta é a única frase, e existe uma ambiguidade: nâo sabemos se a comprovinciana mora na casa, ou na rua, podemos aproveitar a deixa para supor que ela mora na casa. De fato, também năo é possível saber se a comprovinciana está na casa neste período, ou viajando, e por isso empresta a propriedade. Mas nesse mar de ambiguidades, escolhemos pensar que náo somente ela mora na casa, como lá fica, discretamente, quando os amantes se encontram.) Nessa posiçăo, ela funciona como um Cyrano de Bergerac, ajudando um romance, quando queria na realidade ser a protagonista dele. Observando que năo terá futuro mesmo com Camilo, vai até Vilela, denuncia a esposa e o "amigo da onça", e se justifica: aceitei que eles se vissem na minha casa apenas para que eu soubesse com certeza que o fato era real, e năo denunciasse com base numa mentira. Furioso, Vilela manda chamar os dois no momento que julga mais apropriado para matá-los.

3) Quiçás o interesse da dona da casa seja um pouco distinto. Apaixonada por Vilela desde a mais tenra juventude, nutre a esperança de que, se ele descobrir que a esposa dele o trai, acabará unindo-se em laços matrimoniais com ela. Assim, "amiga da onça" de Rita, oferece a casa com promessa de segredo, e na primeira oportunidade conta tudo para Vilela. Após os assassinatos, que saem nos jornais, e a prisấo de Vilela, ela passa a visitá-lo todos os domingos na prisâo. Ao fim de cinco anos, com a liberaçăo (o assassinato era justificado, explicaram, daí a pena curta), Vilela pede-a em casamento.

Mas talvez o problema náo seja se Rita está "certa" ou năo, com relaçăo à existência de outros pretendentes. Também pode ser que ela crie essa aparência de preocupaçáo ou medo de perder Camilo, inventando a história de que foi à cartomante, e atuando como se tivesse ciúmes da possível pretendente, apenas para dissimular o verdadeiro sentimento: Rita quer que o relacionamento com Camilo acabe logo, pois ela começou a ser amante de um homem quatro anos mais velho do que ela, e está cansada da presença de Camilo, quatro anos mais novo, e inexperiente. Para que o plano dela dê certo, ela precisa que Camilo decida se afastar: somente assim nâo recairâo sobre ela suspeitas de que anda com outro. Por isso, ela mesma arranja para Camilo receber as "cartas anônimas", e ela, como boa mulher dissimulada (foi chamada, como mencionado acima, de "uma serpente" no início do conto (134)), finge sofrer muito com tudo isso. Nesta hipótese, Rita é como a Capitu da cabeça de Bentinho.

A continuaçăo desta hipótese é que, com a confusăo entre marido e dois amantes, ocorre que um dia Rita decide suicidar-se, mas năo tem coragem. Por isso, conta tudo para o marido, sabendo que ele irá matá-la. Entretanto, em vez de matá-la, ele grita: Quero provas! Quero que o próprio venha aqui e me diga que tudo isso é verdade. Assim, terei o prazer de matar os dois ao mesmo tempo! O outro, que é Camilo - pois apesar de ter a morte em frente, Rita năo teve coragem de falar do mais velho também - demora demais, por causa do carro que caiu no meio do caminho. Nesse meio tempo, Rita arrepende-se. Ela grita: Fui tonta! Fui tonta! Tenha piedade de mim! Năo nos mate! Eu quero viver! Entretanto, é tarde demais. O sangue já está fervendo nas veias de Vilela, e ele brada: mais uma palavra, e eu a matarei imediatamente! Ela, que é tonta, continua a gritar: por favor, năo me mate! Nessa hora, ele atira. Suado de tensăo, decide abrir a janela, e vê Camilo chegar. Antes que este bata à porta, o traído a abre, e entăo ocorre a cena final do conto. 
Faltou mencionar que, nesse enredo, Rita pediu à cartomante para redigir as cartas; primeiro, pois ninguém reconheceria a letra dela; depois, por saber que ela seria sensível a apelos financeiros. A cartomante aceita, e assim é que ela vem a saber de tantos detalhes importantes sobre a vida de Camilo e Rita. Isso explica porque ela intui perfeitamente o que dizer quando Camilo chega à sua sala.

Mas existe uma outra possibilidade para o desfecho, no caso de Rita ter dois amantes: Camilo e o segundo, que aqui batizamos de Trujilio. Vilela escuta comentários sobre o relacionamento de sua esposa com Trujilio, e fica desnorteado. Para saber se é tudo verdade ou nâo, decide chamar um grande amigo à sua casa, com quem possa se confidenciar. Pensa, e decide que este grande amigo é Camilo, quem ele já năo vê há tanto tempo. Vilela pensa que Camilo saberá guardar o segredo da sua angústia - e crê que, se ele souber de alguma coisa, contará até o fim. Atordoado, Vilela escreve o bilhete para Camilo, pedindo que este venha imediatamente. No meio tempo, prepara a arma para ameaçar Rita. Na verdade, năo pretende assassiná-la. Quer apenas que, pelo terror, ela reconheça que errou, e admita que ficou com Trujilio, se foi isso o que aconteceu. A dúvida é que é a pior sensaçăo para ele. Ocorre que ao ver a arma, Rita pensa que ele realmente irá disparar: năo só nela ela, como no amante mais velho, que ela de fato havia visto pela manhă, e se expusera mais do que o comum. É assim que, no que ela pensa ser um grande gesto de amor para com o amante preferido, ela vai - com seu jeito de tonta - e diz a Vilela que ele está absolutamente enganado. Ela sim tem um amante, mas năo é Trujilio: é Camilo. Nesta hora, Vilela, que como mencionávamos, náo pensava matá-la, muda de ideia, e com a raiva nos píncaros, atira em Rita. Vai logo para a janela, ansioso para que Camilo chegue logo, para que possa matá-lo também.

Quem é esta cartomante? A primeira hipótese que aqui oferecemos é que Rita é a cartomante. Neste caso, a narrativa é muito simples: Rita conta para seu amante, Camilo, que foi a uma cartomante, objetivando com isso testar a reaçăo dele, saber seu nível de tolerância, e objetivando deixar nele o gosto de quem sabe ir um dia à cartomante também. Caso ele fosse, ela poderia escutar tudo o que ele revelaria sobre seus amores, além de ganhar dinheiro. Sim, pois faltou dizer que Rita ama o dinheiro, e entrou a ser cartomante mais por esse motivo que qualquer outro. Quando ela vê pela janela que Camilo está chegando, Rita sente medo de năo conseguir se disfarçar bem o suficiente. Por isso, pede para a cliente que estava ali antes, uma italiana, para trocar de roupa com ela, e atuar como cartomante. Caso faça isso, ficará com cinquenta por cento do pagamento. Como a italiana precisa do dinheiro para a passagem de navio que a levará de volta à Europa, o que é previsâo de Rita, aceita. É por causa do tempo que levam para trocar de roupa, e para Rita esconder-se bem no armário, que Camilo tem de bater à porta algumas vezes antes de que alguém abra.

Assim que ele vai embora, Rita está tăo apavorada, que corre para casa, chegando antes de Camilo, que para lá vai tendo recebido o bilhete de Vilela. Como ela chega em casa com as roupas da italiana, o marido percebe que ela aprontou alguma, e ela confessa tudo: que trabalha de cartomante três vezes por semana, pelo sabor do dinheiro. Indignado, o marido pega o revólver na gaveta e atira. Somente após atirar, ele se dá conta do que fez: entăo vai à janela, para ver se alguém passava por lá. Nisso, vê Camilo, que entâo ele se lembra que havia convidado com urgência para que ele esclarecesse um ponto relativo ao mercado internacional. Desesperado pela hipótese 
de Camilo ter ouvido o tiro e saber de tudo, vindo a denunciá-lo, Vilela tem o reflexo de mandá-lo entrar para, enquanto toma um choque pela imagem de Rita ensanguentada, quase perdendo os sentidos, encontrar a brecha para atirar nele, sem risco de perder a mira.

Finalmente, é possível considerar as hipóteses de que Rita trabalha como cartomante năo apenas pelo prazer do dinheiro, mas também por divertimento. Ela quer a todo modo sair da vida de tédio em que vive, entre casa e amantes. A técnica foi aprendida com a máe de Camilo que, como aprendemos, sempre fora supersticiosa, e morreu num "desastre" náo explicado. Para quem morava no Rio na época, e conhecia os segredos de estado, o desastre era um marco bem conhecido: foi uma invasáo da polícia a todas as casas de leituras de cartas, máos, borras de café e coisas semelhantes. A máe de Camilo morrera com o susto, ao ter a polícia invadindo a casa onde trabalhava. Desde entâo, os que quiseram continuar trabalhando com tais coisas no Rio de Janeiro tiveram sempre de deixar as janelas fechadas.

Para Camilo, tudo isso era um tabu, que ele queria esquecer. Ele jamais teria coragem de assumir em sociedade que sua mâe havia sido uma cartomante, e que morrera com as cartas na mesa. Tinha muita vergonha daquele capítulo de sua vida, e mesmo Rita, que o consolara, năo sabia de nada disso. Por isso, quando conversa com Rita, e ela revela que vai à cartomante, ele tenta rir e mudar de assunto. "Onde é a casa?", pergunta para mostrar-se desinformado, quando na realidade já sabe exatamente onde é. Náo quer parecer curioso demais, e prefere mudar logo de assunto: ri e joga "Tu cres deveras nessas cousas?", evitando assim que ela fale mais sobre a casa, ou perceba algo em seus traços de expressăo.

Quando Camilo desce a rua, e olha para a casa da cartomante, lembra-se de sua măe, que fora ali a cartomante por tanto tempo. Ele tem medo de que sua amante se envolva com coisas no mesmo caminho, nâo somente pelo elemento da superstiçáo, mas pelo risco de a polícia aparecer, e Rita ficar para sempre traumatizada. É tarde demais, pois a essa altura Rita já é cartomante, revezando-se com uma italiana. Ambas aprenderam da măe de Camilo, muito antes de ela morrer no desastre, mas a italiana sempre teve mais sucesso.

\section{O COMENTÁRIO SOBRE A CAUSA SECRETA NO TEXTO DE MUSSA}

Com relaçăo a A Causa Secreta, apenas faltou dizer que o marido a contamina com a doença, para poder assistir a ela sucumbindo. Ele planejava fazer experimentos com ela e por isso foi ele quem introduziu o rival em casa. A propósito, introduzir rivais em casa vem a ser coisa mais ou menos comum nas histórias de Machado, mas neste caso a verdade é que planejava também fazer com o rival o que estava ensaiando com o rato. E quando ri, é por antecipar a experiência.

Será que Mussa, além de estar dialogando com Machado de Assis, está ao mesmo tempo construindo uma paródia do universo acadêmico, das enciclopédias e do mundo cultural institucionalizado? Bem, de um modo ou de outro, é certo que seu texto desafia o leitor, provocando uma imersáo no conto original e suscitando questionamentos novos. Esperando, neste contexto, haver contribuído para o exercício de releitura reflexiva, convidamos todos a prosseguirem com esta jornada analítica, provocadora. 


\section{REFERÊNCIAS}

AGUIAR, Luiz Antonio. Recontando Machado. In.: Org. Rio de Janeiro: Ed. Record. 2008. ASSIS, Machado. Contos escolhidos. Rio de Janeiro: Editora Globo. vol. 17. 